Analytical And Bioanalytical Chemistry

April 2015, Volume 407 Issue 11 Pages 2985-2996

http://dx.doi.org/10.1007/s00216-014-8250-5

http://archimer.ifremer.fr/doc/00320/43138/

(C) Her Majesty the Queen in Right of Canada as represented by:

National Research Council of Canada 2014

\title{
A mussel (Mytilus edulis) tissue certified reference material for the marine biotoxins azaspiracids
}

\author{
McCarron Pearse ${ }^{1,2,{ }^{*}}$, Giddings Sabrina D. ${ }^{1}$, Reeves Kelley L. ${ }^{1}$, Hess Philipp ${ }^{2,3}$, Quilliam Michael A. ${ }^{1}$ \\ ${ }^{1}$ Natl Res Council Canada, Measurement Sci \& Stand, Biotoxin Metrol, Halifax, NS B3H 3Z1, Canada. \\ 2 Inst Marine, Galway, Ireland. \\ ${ }^{3}$ Ifremer, Rue de l'île d'Yeu, Nantes, CEDEX 03, France \\ * Corresponding author : Pearse McCarron, email address : pearse.mccarron@nrc-cnrc.gc.ca
}

\begin{abstract}
:
Azaspiracids (AZAs) are lipophilic biotoxins produced by marine algae that can contaminate shellfish and cause human illness. The European Union (EU) regulates the level of AZAs in shellfish destined for the commercial market, with liquid chromatography-mass spectrometry (LC-MS) being used as the official reference method for regulatory analysis. Certified reference materials (CRMs) are essential tools for the development, validation, and quality control of LC-MS methods. This paper describes the work that went into the planning, preparation, characterization, and certification of CRM-AZA-Mus, a tissue matrix CRM, which was prepared as a wet homogenate from mussels (Mytilus edulis) naturally contaminated with AZAs. The homogeneity and stability of CRM-AZA-Mus were evaluated, and the CRM was found to be fit for purpose. Extraction and LC-MS/MS methods were developed to accurately certify the concentrations of AZA1 $(1.16 \mathrm{mg} / \mathrm{kg})$, AZA2 $(0.27 \mathrm{mg} / \mathrm{kg})$, and AZA3 $(0.21 \mathrm{mg} / \mathrm{kg})$ in the CRM. Quantitation methods based on standard addition and matrix-matched calibration were used to compensate for the matrix effects in LC-MS/MS. Other toxins present in this CRM at lower levels were also measured with information values reported for okadaic acid, dinophysistoxin-2, yessotoxin, and several spirolides.
\end{abstract}




\section{Graphical abstract}

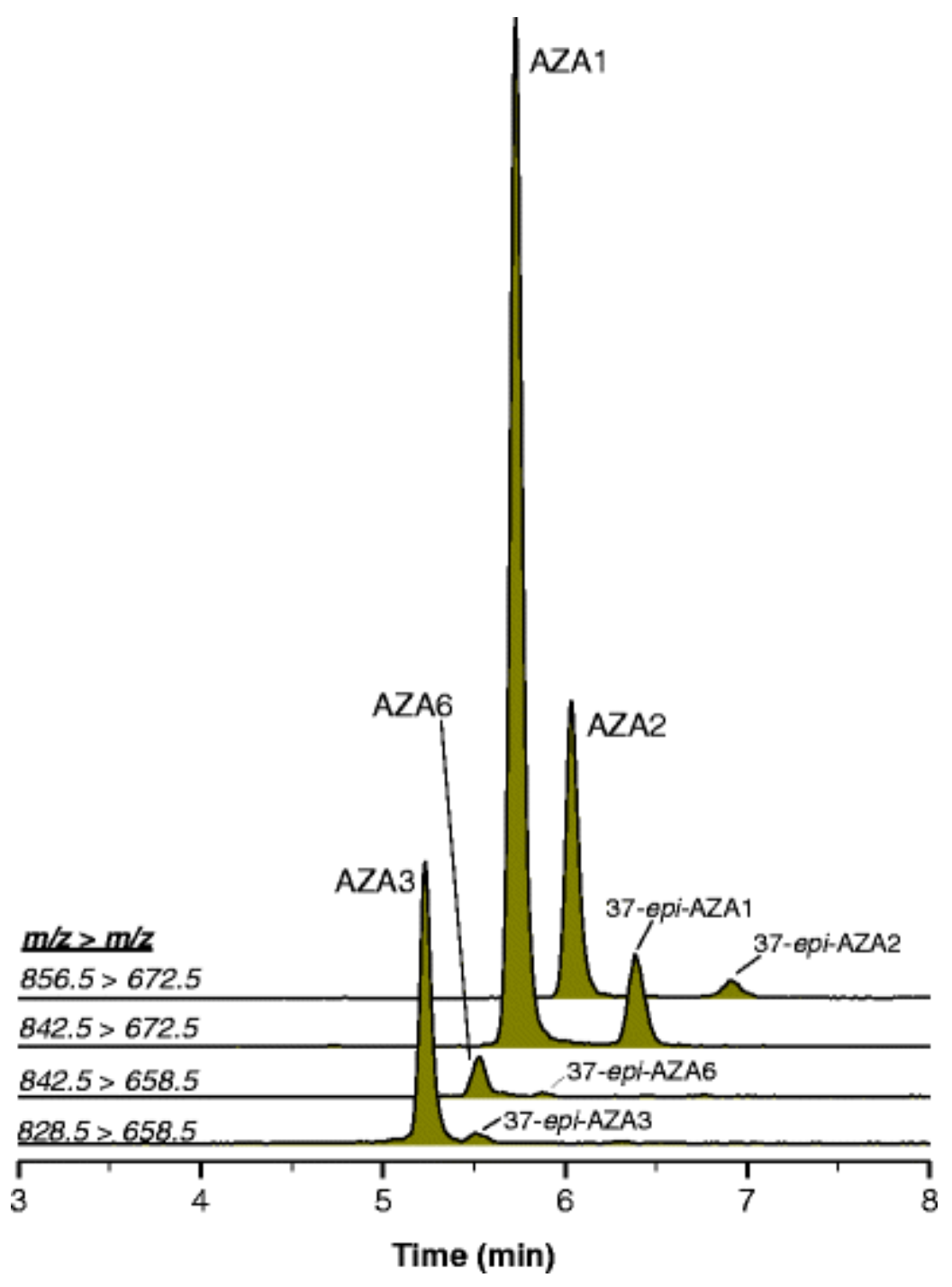

Keywords : Azaspiracids, Seafood safety, Matrix certified reference material, Liquid chromatographymass spectrometry, Matrix effects 


\section{Introduction}

In 1995, several people developed a gastrointestinal illness following consumption of mussels (Mytilus edulis) harvested off the coast of Ireland [1]. The illness was eventually attributed to azaspiracids (AZAs), a very potent class of previously unreported marine biotoxins [2,3]. The structure of AZA1 was reported in 1998 [2] and then revised in 2004 [4]. Subsequently, much work has been completed on the identification and structural elucidation of a host of AZA analogues and isomers [4-9]. The structures of AZA1-10 are shown in Fig. 1. AZAs have been found in many locations including Western Europe [10-13], North West Africa [14], North America [15] and in Japan [16]. AZAs are produced by Azadinium spinosum, a small dinoflagellate first isolated from the North Sea [17,18], which was later found in Western Europe [19]. The major AZA structural variants are produced either directly by Azadinium spinosum, through metabolism in shellfish, or by conversion during processing of shellfish [19-21].

The regulated AZAs are resistant to cooking [22], making it essential that shellfish are strictly monitored to ensure the safety of consumers and the production industry. Only AZA1-3 have been found to be of toxicological importance [2,8] and the regulatory limit of $160 \mathrm{mg} / \mathrm{kg}$ (expressed as AZA1 toxic equivalents) has been set by the European Union [23]. A report by the European Food Safety Authority suggested that these limits should be reduced [24].

The traditional mouse bioassay does not provide the required sensitivity, selectivity or accuracy to adequately implement the regulatory limit for AZAs [25]. An amendment to the EU regulation regarding testing methods [26] has designated liquid chromatography-mass spectrometry (LC-MS) as the official reference method for determination of AZAs in shellfish. A number of alternative methods for AZA analysis have also been reported [27,28]. 
Reference materials (RMs) are important for the development and quality control of analytical methods such as LC-MS. Certified reference material (CRMs) are essential for validation and assessment of analytical determinations and for establishing accuracy and traceability. Considerable efforts have been made in the production of AZA calibration standards $[29,30]$ and the availability of pure standard CRMs for AZA1-3 for instrument calibration for several years has facilitated the implementation of LC-MS methods for regulatory monitoring programs. Up until this point, however, there has not been a matrix CRM available for AZAs. Indeed, the availability of matrix CRMs for all classes of shellfish toxins has been somewhat limited with the National Research Council providing mussel tissue CRMs for domoic acid and okadaic acid. More recently an oyster tissue CRM for paralytic shellfish toxins has been produced by CEFAS [31]. Matrix CRMs are designed to assess the performance of entire analytical methods, including: testing of extraction methods; assessment of matrix effects associated with a particular method; and evaluation of the accuracy of the final measurement or determination step. Ideally, matrix CRMs for seafood toxins should be prepared from naturally contaminated tissues.

This paper describes the planning, preparation and certification of a mussel (Mytilus edulis) matrix CRM for AZAs. The homogeneity and stability of the candidate CRM was assessed. Extraction, calibration and LC-MS analysis methods were developed to ensure the highest degree of accuracy when assigning values to the CRM, and uncertainties were assigned following standardized ISO procedures. Finally, CRM-AZA-Mus was screened for the presence of other common lipophilic toxins. 


\section{Material and Methods}

\subsection{Chemicals and reagents}

HLPC grade acetonitrile, glass-distilled methanol $(\mathrm{MeOH})$, hydrochloric acid $(\mathrm{HCl})$ and sodium hydroxide $(97 \%)(\mathrm{NaOH})$ were obtained from Caledon (Georgetown, ON, Canada). Formic acid ( $>98 \%$ ACS grade) was obtained from EMD (Gibbstown, NJ, USA). Ammonium formate (99\%), ammonium acetate (99\%), pepsin (porcine gastric mucosa, $\geq 2,500$ units/mg protein), ethoxyquin, oxytetracylcine, erythromycin and ampicillin were obtained from Sigma-Aldrich (Oakville, ON, Canada). Bakerbond C8-bonded silica $(40 \mu \mathrm{m})$ was obtained from Mallinckrodt Baker Inc. (Philipsburg, N.J., USA). All water used was purified with a Milli-Q water purification system (Millipore Corp., Billerica, MA, USA) (18.2 $\mathrm{M} \Omega \mathrm{cm}$ at $25^{\circ} \mathrm{C} ;<1 \mathrm{ppb}$ TOC).

Certified calibration solutions of AZA1-3, okadaic acid (OA), dinophysistoxin-1 (DTX1), DTX2, 13-desmethylspirolide-C (13-desMe-SPX-C), pectenotoxin-2 (PTX2), and yessotoxin (YTX) were provided by the National Research Council of Canada (NRCC, Halifax, NS, Canada). A blank mussel tissue CRM (CRM-Zero-Mus) was also provided by NRCC.

\subsection{Heat treatment studies}

Uncooked mussels harvested in Bantry Bay (2001, Southwest Ireland) were removed from freezer storage $\left(-20^{\circ} \mathrm{C}\right)$ and defrosted before shucking. Whole flesh was removed and homogenized using a Waring blender. Aliquots $(2 \mathrm{~g})$ were transferred to $5 \mathrm{ml}$ glass reaction tubes (Wheaton, Millville, NJ, USA). The tubes were sealed tightly with PVDC lined screw caps and aliquots $(\mathrm{n}=3)$ were heated for $10 \mathrm{~min}$ in an oil bath at temperatures ranging from $50{ }^{\circ} \mathrm{C}$ to $150{ }^{\circ} \mathrm{C}$ in $10^{\circ} \mathrm{C}$ increments. 
To determine if AZA decarboxylation was complete in the stock mussel tissues a separate trial was conducted in which a sample of the steam cooked Bruckless mussel tissue (Donegal, Ireland, 2005) was allowed to thaw and then placed in an oven at $95{ }^{\circ} \mathrm{C}$ for $20 \mathrm{~min}$. Prior to heating the tissue temperature was $9.5^{\circ} \mathrm{C}$ and afterwards it was $80^{\circ} \mathrm{C}$.

\subsection{Preparation of CRM-AZA-Mus}

The AZA-contaminated mussels were retrieved from Bruckless, Donegal, Ireland in September 2005. The mussels were steam cooked immediately after harvesting, vacuum packed in $1 \mathrm{~kg}$ lots and stored at $-20^{\circ} \mathrm{C}$ until use. AZA-free mussels were harvested from New London Bay, Prince Edward Island, Canada, in April 2005. These mussels were also steam cooked prior to storage at $-20{ }^{\circ} \mathrm{C}$.

AZA-contaminated $(6.58 \mathrm{~kg})$ and AZA-free tissues $(13.2 \mathrm{~kg})$ were combined by passing through a Comitrol 3600 food cutter (Urschel Laboratories Inc., Valparaiso, IN, USA) equipped with $020-020$ blades a total of three times. The Comitrol was rinsed with $1 \mathrm{~kg}$ of water after the second and third passes and this was combined with the homogenate. The Comitrol was then fitted with 010-010 cutting blades and the homogenate was passed through while mixing in an additional 5.26 L of water. Stabilisers (6.5 g each of ethoxyquin, erythromycin, oxytetracycline and ampicillin) were mixed with $3.58 \mathrm{~L}$ of water and then added to the homogenate before two final passes through the Comitrol (010-010) with an additional $2.47 \mathrm{~L}$ of water. The material was collected in two separate $25 \mathrm{~L}$ containers and the moisture content determined to be $85 \%$ using an OHAUS moisture determination balance (Cole-Parmer, IL, USA). Both containers of homogenate were blended using a Polytron ${ }^{\mathrm{TM}}$ (Kinematica, Lucerne, Switzerland) $(5,000 \mathrm{rpm}$, $10 \mathrm{~min}$ ) before degassing and storing overnight at $4{ }^{\circ} \mathrm{C}$. The next day the tissues were degassed 
under vacuum and $\mathrm{N}_{2}$ was bubbled through the homogenate prior to re-combining. The homogenate was then transferred to a container equipped with a mechanical stirrer (Lightnin Labmaster Mixer, L1U1O-A200, Cole Parmer, IL, USA) set at $750 \mathrm{rpm}$. This container was inturn placed in larger container with ice in order to avoid heating and evaporation of water from the homogenate during the dispensing step. A Masterflex dispensing pump (Cole Parmer) was calibrated to dispense $8 \mathrm{~g}(7.9-8.2 \mathrm{~g})$ of homogenate into $10 \mathrm{~mL}$ polypropylene bottles. Filled bottles were purged with argon before hermetically sealing with strips of trilaminate foil using a MKIII heat-sealing machine (SiS Ltd., Chadwicks of Bury, UK). The bottles were then labeled, screw capped and stored at $-20^{\circ} \mathrm{C}$. The bottles were transported on dry-ice to the Agriculture and Agri-Food Canada facility in Ste-Hyacinthe (Quebec, Canada) for gamma irradiation. The irradiation dose received by all bottles was in the range of 14.3 to $19.4 \mathrm{kGy}$ ( $\gamma$-irraditon, source cobalt 60) [32]. The bottles were returned frozen to the NRCC in Halifax for sealing (12ASD Heat Sealer, Sentinal Packaging Inc., Hyannis, MA, USA) inside trilaminate lightproof foil pouches (Retort Pouches, ISE USA Inc). A total of 3697 bottles were pouched and then stored at $-80{ }^{\circ} \mathrm{C}$. The production process for CRM-AZA-Mus is summarized in Fig. 2.

\subsection{Sample preparation}

\subsubsection{Method A (homogeneity and stability studies)}

The entire content of a CRM-AZA-Mus bottle $(8.0 \pm 0.2 \mathrm{~g})$ was transferred to a $50 \mathrm{~mL}$ centrifuge tube, weighed and extracted in 3 steps with $30 \mathrm{~mL}$ aliquots of $\mathrm{MeOH}$ for each step. A multi tube vortex mixer (Model: DVX 2500, VWR, West Chester, PA, USA) was used for the first extraction step (2500 rpm, $2 \mathrm{~min}$ ) prior to centrifuging (3000 $\mathrm{g}, 10 \mathrm{~min})$ and decanting the liquid phase. A Polytron ${ }^{\mathrm{TM}}(10,000 \mathrm{rpm}, 1 \mathrm{~min})$ was used for the second extraction step. Vortex 
mixing was used again for the final extraction step. The decanted extracts from all three steps were combined in a $100 \mathrm{~mL}$ volumetric flask and the contents were made to volume with $\mathrm{MeOH}$. Aliquots of the final extracts were passed through $0.45 \mu \mathrm{m}$ regenerated cellulose filters (Millipore Corp, Billerica, MA, USA) prior to analysis (note: all extracts prepared for this work were filtered in this manner).

\subsubsection{Method B (certification by liquid solid extraction (LSE))}

Aliquots $(8 \mathrm{~g})$ were extracted in $50 \mathrm{~mL}$ centrifuge tubes in 4 steps with $22 \mathrm{~mL}$ aliquots of $\mathrm{MeOH}$ for each step. Vortex mixing was used for the first extraction step (see above), followed by centrifugation $(3950 \mathrm{~g}, 10 \mathrm{~min})$ and decantation. The second and third extraction steps used an Omni prep homogenizer (Omni Int., Kennesaw, GA, USA) (10,000 rpm, 3 min). Vortex mixing was used again for the final step. The extracts from all four steps were combined in $100 \mathrm{~mL}$ volumetrics and brought to volume with $\mathrm{MeOH}$.

\subsubsection{Method C (certification by matrix solid phase dispersion (MSPD))}

An MSPD [33] procedure was developed for extraction of AZAs. An aliquot (0.5 g) was weighed into a polystyrene weigh boat. The tissue was ground with $2.0 \mathrm{~g}$ of Bakerbond C8-silica using a glass mortar and pestle. Once the sample was ground thoroughly with the silica, it was transferred to a $7 \mathrm{~mL}$ glass SPE column pre-packed with $0.25 \mathrm{~g}$ of clean C8-silica placed between two PTFE frits. The sample was packed carefully into the tube, ensuring no voids, and a piece of glass wool was placed on top. The SPE column was attached to a vacuum manifold, equipped with $10 \mathrm{~mL}$ volumetric flasks for collection. The mortar and pestle were rinsed with $3 \mathrm{~mL}$ of $\mathrm{MeOH}$, and the rinse transferred to the MSPD tube. The MSPD tube was then eluted 
drop wise under controlled vacuum and eluted with additional $\mathrm{MeOH}$ until the collection flask was filled almost to volume. The sample was made to $10 \mathrm{~mL}$ using $\mathrm{MeOH}$.

2.4.4 Method D (minor analog profiling and protein binding work)

Samples $(2 \mathrm{~g})$ were extracted with a two-step procedure using $4.5 \mathrm{~mL}$ aliquots of $\mathrm{MeOH}$. A hand-held variable speed Omni prep homogenizer was used (15,000 rpm, $3 \mathrm{~min})$ for both steps. The resulting supernatants were combined in a $10 \mathrm{~mL}$ volumetric flask and the sample was made to $10 \mathrm{~mL}$ using $\mathrm{MeOH}$.

\subsubsection{Ester hydrolysis}

To hydrolyse esters of the OA group toxins $1 \mathrm{~mL}$ aliquots of CRM-AZA-Mus extract (prepared with Method D) were placed in an HPLC vial, $125 \mu \mathrm{L}$ of $2.5 \mathrm{~N} \mathrm{NaOH}$ was added, and the mixture was placed in a water bath at $76{ }^{\circ} \mathrm{C}$ for $40 \mathrm{~min}$. The samples were cooled and neutralized with $125 \mu \mathrm{L}$ of $2.5 \mathrm{~N} \mathrm{HCl}$ before filtration prior to LC-MS analysis for OA, DTX1 and DTX2.

\subsection{Liquid chromatography-mass spectrometry (LC-MS)}

LC-MS analyses for this work were performed on an Agilent 1200 LC system (Palo Alta, CA, USA) connected to a Q-TRAP API4000 mass spectrometer (AB-Sciex, Concord, ON, Canada), equipped with a turbospray ionization source. 


\subsubsection{Method 1 (homogeneity and stability)}

A $50 \times 2.1 \mathrm{~mm}$ i.d. column packed with $3 \mu \mathrm{m}$ BDS Hypersil-C8 (Thermo Scientific, Waltham, MA, USA) was used with a binary mobile phase of water (A) and acetonitrile:water 95/5 (B), both containing $2 \mathrm{mM}$ ammonium formate and $50 \mathrm{mM}$ formic acid. Gradient elution was from $30-100 \%$ B over $8 \mathrm{~min}$, at $250 \mu \mathrm{L} / \mathrm{min}$ at $20^{\circ} \mathrm{C}$, with $5 \mu \mathrm{L}$ injections. The $\mathrm{MS}$ was operated in positive selected reaction monitoring $(\mathrm{SRM})$ mode: AZA1 $(842.5 \rightarrow 672.5 \& 362.3)$; AZA6 (842 $\rightarrow 658.5 \& 362.3) ;$ AZA2 $(856.5 \rightarrow 672.5 \& 362.3) ;$ AZA3 $(828.5 \rightarrow 658.5 \& 362.3)$. The collision energies (CEs) for AZA1-3 were set to 65 and $75 \mathrm{eV}$ for the $672.5 / 658.5$ and 362.3 fragment transitions respectively, and the declustering potential (DP) was $50 \mathrm{eV}$ for all. The source temperature was $350^{\circ} \mathrm{C}$ and the ion-spray voltage was 5500 .

\subsubsection{Method 2 (certification measurements)}

A $50 \mathrm{~mm} \times 2.1$ i.d. column packed with $2.5 \mu \mathrm{m}$ Luna C18(2) HST (Phenomenex, Torrence, CA, USA) was eluted with a binary mobile phase of water (A) and acetonitrile/water (95/5) (B) each containing $5 \mathrm{mM}$ ammonium acetate ( $\mathrm{pH}$ 6.8). A gradient was run from $25-100 \%$ B over 5 min at $350 \mu \mathrm{L} / \mathrm{min}$ at $15^{\circ} \mathrm{C}$, with $5 \mu \mathrm{L}$ injections. The MS was operated in positive ion SRM mode as described for AZA1-3 in the homogeneity and stability section above. This procedure was validated in-house for AZA determinations.

\subsubsection{Method 3 (analysis of additional AZA toxins)}

Additional non-certified AZA analogs were measured using Method 2 with some modifications. The gradient was run from $25-100 \% \mathrm{~B}$ over $20 \mathrm{~min}$ at $250 \mu \mathrm{L} / \mathrm{min}$ at $15{ }^{\circ} \mathrm{C}$. Analysis was in positive ion SRM mode screening for all AZA analogs as reported by Rehmann et al. [7]. 
2.5.4 Method 4 (analysis of additional lipophilic toxins)

CRM-AZA-Mus was screened for a range of lipophilic toxins using a previously reported method [35].

\subsubsection{Method 5 (analysis of spirolides)}

A $50 \times 2.1 \mathrm{~mm}$ i.d. column packed with $2.5 \mu \mathrm{m}$ Luna C18(2) HST eluted with a binary mobile phase of water (A) and acetonitrile/water (95/5) (B), each containing $5 \mathrm{mM}$ ammonium acetate (pH 6.8). A gradient was run from $25-75 \%$ over $12 \mathrm{~min}$ at $300 \mu \mathrm{L} / \mathrm{min}$, maintaining the column at $20{ }^{\circ} \mathrm{C}$, with $5 \mu \mathrm{L}$ injections. The MS was operated in positive ion SRM mode: 13-desMe-SPXC, SPX-G (692.5 $\rightarrow$ 164.1); 13-desMe-SPX-D, SPX-B, PnTX-G (694.5 $\rightarrow 164.1)$; SPX-D (706.6

$\rightarrow 164.1)$; SPX-C (708.5 $\rightarrow$ 164.1); unknowns $(710.6 \rightarrow 164.1,722.5 \rightarrow 164.1,782.6 \rightarrow 164.1)$ CEs and DPs were 70 and $80 \mathrm{eV}$ respectively. The source temperature was $300{ }^{\circ} \mathrm{C}$ and the ionspray voltage was 5000 .

\subsection{Calibration and quantitation procedures}

Two different quantitation procedures were used to deal with matrix effects in the LC-MS/MS measurements: standard addition and matrix-matched calibration.

\subsubsection{Standard addition}

Two accurate mixed standard solutions were prepared using AZA1-3 calibrant CRMs for spiking the two different types of extracts. Method B extracts (LSE) were spiked with a solution containing $370 \mathrm{ng} / \mathrm{mL}$ AZA1, $83 \mathrm{ng} / \mathrm{mL}$ AZA2 and $70 \mathrm{ng} / \mathrm{mL}$ AZA3. Method C extracts 
(MSPD) were spiked with a solution containing $220 \mathrm{ng} / \mathrm{mL}$ AZA1, $50 \mathrm{ng} / \mathrm{mL}$ AZA2 and $42 \mathrm{ng} / \mathrm{mL}$ AZA3. Extracts of CRM-AZA-Mus and CRM-Zero-Mus were spiked by mixing $50 \mu \mathrm{L}$ of the appropriate spiking solution with $200 \mu \mathrm{L}$ of the extracts using a Microlab diluter/dispenser (Hamilton Company, Reno, NV, USA). For zero levels, the extracts were spiked with $\mathrm{MeOH}$ containing no toxin. Spiking solutions were also mixed with $\mathrm{MeOH}$ to prepare matrix-free controls. All samples were prepared in triplicate.

\subsubsection{Matrix-matched calibration}

A mixed stock solution was prepared using AZA1-3 calibrant CRMs at concentrations of 706, 176 and $142 \mathrm{ng} / \mathrm{mL}$, respectively. A working solution was made by preparing a 3-fold dilution of this stock, which was subsequently used for preparation of a six-level dilution series with the Microlab. Concentrations were in the range of $706-3 \mathrm{ng} / \mathrm{mL}, 176-0.7 \mathrm{ng} / \mathrm{mL}$ and $142-$ $0.6 \mathrm{ng} / \mathrm{mL}$ for AZA1-3, respectively. Matrix-matched calibration solutions were prepared by mixing $100 \mu \mathrm{L}$ aliquots of each level with $400 \mu \mathrm{L}$ aliquots of CRM-Zero-Mus extract (both LSE and MSPD) using the Microlab. The solutions were also mixed with $\mathrm{MeOH}$ to prepare matrixfree calibration standards. 


\section{Results and Discussion}

\subsection{Design and preparation of CRM-AZA-Mus}

The production of a CRM requires significant planning to ensure fitness for purpose. Analytes of interest must be homogeneously dispersed throughout the material and between bottles. A CRM must also be stable, as potential changes to concentration values during shipping and in storage severely risk the material's usefulness in method development and validation. Homogeneity can be achieved through rigorous blending and mixing of the stock material before and during the bottling stage. Ensuring stability is frequently more challenging, in particular for matrix CRMs, and generally requires more careful research and planning.

Although heat treatment is a common step in stabilization of tissue RMs for shellfish toxins [36,37], previous research on AZA RMs demonstrated problems with heat treatment due to the instability of AZA3 [30]. Heat-treatment was further studied in this work by hermetically sealing raw AZA-contaminated tissue in containers and heating them for 10 min at temperatures ranging from $50-150{ }^{\circ} \mathrm{C}$. As shown in Fig. 3, AZA1 and AZA2 were stable up to $110{ }^{\circ} \mathrm{C}$, with extensive degradation becoming apparent at temperatures above $120{ }^{\circ} \mathrm{C}$. AZA3 showed an increase in concentration from $0.1 \mathrm{mg} / \mathrm{kg}$ at room temperature to $0.7 \mathrm{mg} / \mathrm{kg}$ at $90{ }^{\circ} \mathrm{C}$. This increase was a result of the AZA1 metabolite, AZA17, which was present in the uncooked mussel tissues, decarboxylating to form AZA3 as the tissues are heated [20]. At temperatures greater than $90{ }^{\circ} \mathrm{C}, \mathrm{AZA} 3$ was observed to degrade extensively, with complete decomposition measured at $150^{\circ} \mathrm{C}$. This study confirmed that post-bottling thermal processing $\left(>115^{\circ} \mathrm{C}\right)$ was not an appropriate method for stabilisation of a CRM to be certified for AZAs. However, because of the presence of AZA17 in the matrix, it was important that some heat treatment was carried out on the tissues to eliminate AZA17 before preparation of CRM-AZA-Mus. After 
harvesting, the Bruckless mussels were steamed to assist with shucking. While this process also served to stabilize the AZA3 profile, a trial was performed to determine if decarboxylation was complete. Aliquots $(\mathrm{n}=3)$ of the processed tissues were heated at $95^{\circ} \mathrm{C}$ for $10 \mathrm{~min}$, and no significant change in AZA3 level was observed indicating that the initial heat treatment applied was sufficient $(0.70$ and $0.68 \mathrm{mg} / \mathrm{kg}$ before and after heating, respectively).

The AZA tissues from Bruckless were highly concentrated (approximately 3.0, 0.67 and $0.70 \mathrm{mg} / \mathrm{kg}$ for AZA1-3, respectively). In order to make the CRM more appropriate for end users, in relation to regulatory levels, a 3-fold dilution of the stock tissue was prepared. Whole cooked mussels harvested in Prince Edward Island were used for this dilution as they had no detectable levels of AZAs.

The moisture content of CRM-AZA-Mus was adjusted to $85 \%$ in order to be representative of typical unprocessed mussels. During this moisture adjustment step a number of stabilizing agents were added at a concentration of $0.02 \%(\mathrm{w} / \mathrm{w})$ in the final material. Previous studies have shown that a combination of antioxidant and antibiotics are beneficial for the stability of some shellfish toxins and, importantly, they are beneficial for the stability of the mussel matrix [38].

The last major consideration in the production of CRM-AZA-Mus was whether to include a final stabilization step. As shown, heat treatment $\left(>115^{\circ} \mathrm{C}\right)$ was not a viable method for the stabilization of AZA in matrix RMs. Freeze-drying has been established as a beneficial procedure for AZA RMs $[39,40]$ but the resources required for preparation of a large scale freeze-dried CRM were not available when CRM-AZA-Mus was produced. The decision to proceed with production of a wet tissue homogenate is strengthened when it is considered that this matrix is very similar to the type of wet shellfish samples generally received as part of routine regulatory monitoring programs. Feasibility studies showed that $\gamma$-irradiation was 
suitable as a stabilization procedure for use in the preparation of AZA RMs, and it was demonstrated that the treatment was highly effective in eliminating microbial activity in shellfish tissue RMs after they have been bottled [32]. Irradiation was therefore selected as a post-bottling stabilization process. All bottles received a dose in the range of 14 to $20 \mathrm{kGy}$. The variation in dose received posed no risk to the stability of the AZAs in the mussel matrix [32].

\subsection{Homogeneity and stability}

The homogeneity of CRM-AZA-Mus was assessed following an approach described by van der Veen et al. [41]. Bottles of CRM-AZA-Mus $(n=15)$ were selected from across the fill series and analysed under repeatability conditions. The percent coefficients of variation (\%CVs) were $4.0,3.2$ and $5.1 \%$ for AZA1, -2 and -3 , respectively. The variation between bottles $\left(\mathrm{U}_{c(b b)}\right)$ comprises between-bottle heterogeneity $\left(S_{b b}\right)$ and the variation due to measurement $\left(S_{\text {meas }}\right)$. The latter was estimated taking 4 sub-samples from a single bottle. Uncertainties due to homogeneity $\left(u_{\text {homo }}\right)$ were then established according to Equation 1. Relative homogeneity uncertainty values between 2.2 and 3.5\% were estimated for AZA1-3 in CRM-AZA-Mus.

Equation 1: $\quad S_{b b}=\sqrt{U_{c(b b)}^{2}-S_{\text {meas }}^{2}}$

A large batch of CRM-AZA-Mus was prepared to ensure a continuous supply for a sufficient number of years. It was therefore important to ensure stability of the material over its lifetime. An isochronous stability study was run at $-12,4,18$ and $37^{\circ} \mathrm{C}$ using time points of 14 , 67, 144 and 267 days, maintaining reference samples at $-80{ }^{\circ} \mathrm{C}$ (Table 1). All toxins were stable over 14 days at temperatures up to $+20^{\circ} \mathrm{C}$, suggesting limited risk during shipping and short- 
term handling of CRM-AZA-Mus. Nevertheless, chilled packing will be used as a precaution against fluctuating transport conditions during shipping. All three analytes were found to be stable over the entire duration of the study at -12 and $+4{ }^{\circ} \mathrm{C}$. As previously observed, AZA3 was the least stable analog, with approximately $30 \%$ degradation after 267 days at $+18{ }^{\circ} \mathrm{C}$. At the stress temperature of $37^{\circ} \mathrm{C}, \mathrm{AZA} 3$ is nearly completely degraded by the end of the study period, while AZA1 and AZA2 show significant degradation. For comparison, excellent stability of AZAs was observed in a freeze-dried mussel tissue CRM prepared for multiple groups of lipophilic toxins, in which no detectible degradation was observed after 1 year for AZA1-3 at temperatures up to $+20{ }^{\circ} \mathrm{C}$ [40]. While the freeze-dried matrix clearly provides increased stability over a wet tissue matrix good stability was observed for CRM-AZA-Mus and appropriate transport and storage conditions have been established. Stability monitoring of CRM-AZA-Mus is ongoing. Uncertainties due to stability were established by calculating the uncertainty of the slope $\left(\mu_{b}\right)$ for the $-20^{\circ} \mathrm{C}$ stability data using Microsoft Excel regression statistics (data plotted as $-20^{\circ} \mathrm{C}$ response (relative to reference temperature) against time points). Uncertainties due to stability $\left(\boldsymbol{\mu}_{\text {stab }}\right)$ were calculated according to Equation 2. Relative values for AZA1-3 were 1.3, 2.3 and $0.6 \%$, respectively, and were calculated based on an assigned 1 year shelf life $\left(t_{\text {stab }}\right)$.

Equation 2: $\quad \mu_{\text {stab }}=\mu_{b} * t_{\text {stab }}$

In 2008, Nzoughet et al. reported that AZAs bind to proteins within the mussel tissue matrices [42]. The presence of protein bound AZAs was further suggested in later work examining the stability of AZAs [43]. However, in studies conducted as part of this work there 
was no evidence of significant amounts of protein bound toxins in CRM-AZA-Mus, therefore there is no perceived risk of changes to the certified concentrations (see Electronic Supplementary Material).

\subsection{Certification measurements}

Matrix CRMs are valuable in assessing the performance of entire analytical methods and it is essential that values assigned to the CRM are as accurate as possible. For CRM-AZA-Mus there were several challenges to be considered in the value assignment process. As the analyte was present in a complex matrix, the first challenge was to ensure complete (exhaustive) recovery during the extraction procedure. For CRM-AZA-Mus, two extraction methods were optimized and validated in-house to provide complete recovery. A procedure based on the traditional liquid solid extraction (LSE) approach (Method B) was optimized for CRM-AZA-Mus through a number of experiments examining the number of extraction steps $(n=4)$, the type of solvent $(\mathrm{MeOH})$, and the sample-to-solvent ratio (1:12.5) (see Electronic Supplementary Material). The second extraction procedure (Method C) was based on matrix solid phase dispersion (MSPD). MSPD involves disruption of the sample on a solid support phase, which also maximizes surface area, with subsequent exhaustive elution of the analytes of interest from the sample/silica mixture packed in an SPE tube [44]. The main considerations in development of the MSPD method were the support phase (Bakerbond C8), the sample to support ratio (1:4), solvent $(100 \%$ $\mathrm{MeOH})$, and elution volume $(10 \mathrm{~mL})$ (see Electronic Supplementary Material). The optimized LSE and MSPD methods both gave recoveries $>99 \%$ for AZA1-3 from CRM-AZA-Mus.

The second challenge was accurate quantitation by LC-MS/MS. The complex nature of the mussel matrix made the analysis susceptible to matrix effects, which can enhance or suppress 
electrospray ionization of analytes $[45,46]$. Various approaches to deal with matrix effects in the analysis of shellfish toxins were discussed previously [35]. The methods most applicable to compensate for matrix effects in CRM certification work are standard addition $[47,46]$, matrixmatched calibration [48] and dilution. These methods deal with the matrix effect issues, without the risk of losing analyte during the process, which can be a problem with clean-up procedures such as solid phase extraction. Standard addition and matrix-matched calibration procedures were optimized and validated in-house to ensure that the most accurate results were achieved.

In a previous study, it was demonstrated that AZA1-3 showed linearity of response when spiked into mussel tissue extracts [35]. Therefore, the standard addition experiments on CRM-AZA-Mus were performed using a single toxin spike (spiked at a concentration equal to that of the analyte in the extract) and a zero spike (with $20 \%$ dilution to compensate for spike solution volume) level for both LSE and MSPD extracts. This greatly reduced the number of samples for analysis and ensured that the experiment could be run under repeatable conditions. The standard addition results (Table 2) were in good agreement for the LSE and MSPD extracts. Comparing the standard addition results with those from analysis of the neat extracts with external calibration shows that levels of suppression ranged from $16-24 \%$ for LSE extracts and from $11-21 \%$ for MSPD extracts. The reduced matrix effects associated with the MSPD extracts are due to the higher sample-to-solvent ratio and possibly some clean-up of the extract provided by the MSPD process.

CRM-Zero-Mus extract was used for preparation of matrix-matched calibration standards. Through standard addition experiments, it was shown that AZAs were suppressed to the same extent in CRM-Zero-Mus as they were in CRM-AZA-Mus (see Electronic Supplementary Material). LSE and MSPD extracts of CRM-Zero-Mus were spiked with a mixed 
dilution series of AZA1-3. These matrix-matched calibration curves were then used to quantitate AZA1-3 levels in CRM-AZA-Mus (Table 2). The matrix-matched calibration results on the LSE and MSPD extracts were in very good agreement. The extent of matrix effects was assessed through comparison with calibrants spiked in pure $\mathrm{MeOH}$, and show levels of suppression very similar to those determined by standard addition. Again, matrix suppression was slightly reduced for MSPD extracts.

The occurrence of isomeric forms of the major AZA analogs was previously reported [35], and these have recently been characterised as C37 epimers [49]. The presence of these epimers in CRM-AZA-Mus is illustrated in Fig. 4A and is significant from the point of view of assigning accurate certified values. While not generally separated under acidic conditions (Fig. 4B), it has been established that these epimers can be separated from their parent analogs when using neutral mobile phase conditions [35]. Molar response studies have shown that when monitoring using the LC-MS/MS conditions described for certification in this work, there is no significant difference between the response of AZA1 and its isomer [49]. For assignment of certified values the equivalence of molar response under the conditions used facilitated reporting certified values as a sum of the parent AZA analogs and their respective epimers. A combined concentration value is appropriate as acidic $\mathrm{pH}$ mobile phase systems are frequently used for the analysis of shellfish toxins, including AZAs, and under these conditions the AZA epimers are not resolved. In CRM-AZA-Mus the epimer peak areas correspond to approximately $10 \%$ of the total AZA1 and AZA2 peak areas, and approximately $7 \%$ for AZA3. Only the combined concentrations of AZA1-3 and their isomers are certified in CRM-AZA-Mus. 


\subsection{Assignment of certified values and uncertainties}

For certification of RMs a number of different approaches can be taken [50]. At the NRCC the typical procedure is to assign values based on analyses using two or more independent methods. The methods available for use in a certification exercise vary significantly between analytes and the type of RM being produced. Quantitative ${ }^{1} \mathrm{H}$ nuclear magnetic resonance is an important method for the certification of toxin calibration solution CRMs [51] but this technique is not applicable to matrix materials. The analytical methods available for AZA determination are somewhat limited due to the absence of a suitable chromophore for direct analysis by optical detection methods such as UV and fluorescence. A method based on derivatisation of AZAs with 9-anthryldiazomethane (ADAM) has been developed to enable analysis by LC with fluoresence detection (LC-FLD) [28]. The method has produced accurate results for AZAs in CRM-AZAMus [28]. However, the precision of the ADAM results for CRM-AZA-Mus was not sufficient for certification purposes. The derivatisation step and clean-up procedure involved in the process requires several steps over two days, and it can suffer from matrix effects on the reaction yields. . Therefore, while the ADAM LC-FLD method provided good supporting data for the CRMAZA-Mus, it was not used for certification. The methods for AZA quantitation in the certification exercise were therefore based on LC-MS/MS. The separate LSE and MSPD extractions procedures were optimized for CRM-AZA-Mus to provide complete recovery $(>99 \%)$ and to provide independent approaches for value assignment. Two separate approaches were also taken to compensate for the matrix effects associated with LC-MS analysis of AZAMus extracts (Table 2). The independence of the separate extraction procedures was best complemented by selecting data acquired using separate calibration approaches to deal with matrix effects. Therefore, the final certified values for CRM-AZA-Mus were obtained by using 
data from standard addition on the LSE extracts $(1.184,0.284$ and $0.225 \mathrm{mg} / \mathrm{kg}$ for AZA1-3, respectively) and matrix-matched calibration on the MSPD extracts (1.132, 0.261 and 0.197 $\mathrm{mg} / \mathrm{kg}$ for AZA1-3, respectively). Following ISO guidelines [52] and in-house protocols the two sets of values were combined by taking an average of the mean values of each method, to assign certified values for AZA1-3 in CRM-AZA-Mus: $1.16 \mathrm{mg} / \mathrm{kg}$ for AZA1; $0.27 \mathrm{mg} / \mathrm{kg}$ for AZA2; and $0.21 \mathrm{mg} / \mathrm{kg}$ for AZA3. The uncertainty associated with characterization $\left(\mu_{c h a r}\right)$ was calculated as in Equation 3 from two components: the method dependent uncertainty $\left(\mu_{\mathrm{i}}\right)$ and the uncertainty of the average of the method means $\left(\mu_{\mathrm{R}}\right)$. The method dependent uncertainty $\left(\mu_{\mathrm{i}}\right)$ is the combined uncertainty of the two analytical approaches (standard addition with LSE and matrix-matched calibration with MSPD) that were used to obtain the certified values. Method uncertainties for each of the two approaches were determined first and each included uncertainties associated with extraction, LC-MS and the uncertainty from the CRM calibrant used. These uncertainties for both approaches were then combined to obtain the method dependent uncertainty $\left(\mu_{\mathrm{i}}\right)$. The uncertainty of the average of the method means $\left(\mu_{\mathrm{R}}\right)$ is the uncertainty associated with assigning a value based on the average of a number of values. In the certification of CRM-AZA-Mus data from two different analytical approaches were used. The $\mu_{\text {char }}$ ranged from 0.008 to 0.029 for AZA1-3 (Table 3).

Equation 3: $\quad \mu_{\text {char }}=\sqrt{\mu_{\mathrm{i}}^{2}+\mu_{\mathrm{R}}^{2}}$

The assignment of final combined uncertainties to CRM-AZA-Mus was in accordance with ISO guidelines [52] and the guide to expression of uncertainty in measurement (GUM) [53]. The overall uncertainty estimates $\left(\mathrm{U}_{\mathrm{CRM}}\right)$ include uncertainties associated with batch 
characterization $\left(\mu_{\text {char }}\right)$, between-bottle variation $\left(\mu_{h o m}\right)$ and instability during long-term $\left(\mu_{\text {stab }}\right)$, as expressed in Equation 4.

Equation 4:

$$
\mathrm{U}_{\mathrm{CRM}}=\mathrm{k} \sqrt{\mu_{\mathrm{char}}^{2}+\mu_{\mathrm{hom}}^{2}+\mu_{\mathrm{stab}}^{2}}
$$

The uncertainty components relating to homogeneity, stability, and characterization for AZA1-3 are shown in Table 3. A coverage factor $(k)$ of 2 for a $95 \%$ confidence level was applied to obtain the final expanded uncertainties, and these corresponded to relative uncertainty values of $8.2,8.2$ and $11 \%$ for AZA1-3, respectively.

\subsection{Characterization of additional toxins in CRM-AZA-Mus}

As CRM-AZA-Mus was prepared from naturally contaminated tissues the presence of toxins in additional to those certified was a consideration. CRM-AZA-Mus was analyzed for a range of AZA analogues (Fig. 5) and Table 4 shows indicative concentrations of AZA4-10 present. A range of additional minor AZA analogues [7] were also detected (data not shown).

The CRM was screened for a broad suite of lipophilic toxins including OA, DTXs, YTXs and PTXs using a previously reported method [35]. Indicative concentrations of OA and DTX2, total OA concentrations including esters, and YTX are reported in Table 5. Finally, a number of cyclic imines group toxins were detected in the CRM, which included several spirolides (SPX) and pinnatoxin-G (PnTX-G) (see Electronic Supplementary Material). The majority of these cyclic imines were present at trace levels and were not quantitated. 


\section{Conclusions}

Based on prior experience and feasibility studies on RMs for AZAs, CRM-AZA-Mus was prepared from naturally contaminated mussels and packaged as a wet homogenate. Anti-oxidants and antibiotics were added as stabilizers and gamma-irradiation was used as post-bottling stabilization process. AZA levels are appropriate for laboratories that perform testing for AZAs on a routine basis in a regulatory setting. The homogeneity and stability of the CRM were comprehensively assessed and the CRM was found to be fit for purpose. Fully exhaustive extraction procedures were developed and a number of different approaches were used to account for the matrix effects associated with analysis by LC-MS. Certified values and associated uncertainties were assigned following internationally accepted procedures for the production of CRMs. As the CRM was prepared from naturally contaminated tissues, a range of additional AZA analogues were identified in the matrix, along with toxins from the DSP and YTX groups, although certified values were not assigned for these analytes. CRM-AZA-Mus will be a valuable tool for analytical labs in the development, validation and quality control of methods for monitoring AZAs.

\section{Acknowledgements}

The following staff members at the $\mathrm{NRC}^{1}$, the Canadian Institute of Fisheries and Technology ${ }^{2}$ and Agriculture and Agrifood Canada ${ }^{3}$ contributed to the production and certification of CRM-AZA-Mus: Dian Marciniak ${ }^{1}$, Sheila Crain ${ }^{1}$, Elliott Wright $^{1}$, Ruth Perez-Calderon ${ }^{1}$, Douglas Singer ${ }^{2}$, Anne Timmins ${ }^{2}$, John Thompson ${ }^{2}$ and Bruno Laventure ${ }^{3}$.

This project was supported by the ASTOX project (ST/02/02, 2003-2006) funded through the Irish National Development Plan (NDP) and the Irish Marine Institute. 


\section{References}

1. McMahon T, Silke J (1996) Winter toxicity of unknown aetiology in mussels. Harmful Algae News 14:2

2. Satake M, Ofuji K, Naoki H, James KJ, Furey A, McMahon T, Silke J, Yasumoto T (1998) Azaspiracid, a New Marine Toxin Having Unique Spiro Ring Assemblies, Isolated from Irish Mussels, Mytilus edulis. J Am Chem Soc 120:9967-9968

3. Twiner MJ, Rehmann N, Hess P, Doucette G (2008) Azaspiracid Shellfish Poisoning: A Review on the Chemistry, Ecology, and Toxicology with an Emphasis on Human Health Impacts. Marine Drugs 6 (2):39-72. doi:10.3390/md20080004

4. Nicolaou KC, Vyskocil S, Koftis TV, Yamada YMA, Ling T, Chen DYK, Tang W, Petrovic G, Frederick MO, Li Y, Satake M (2004) Structural Revision and Total Synthesis of Azaspiracid-1, Part 1: Intelligence Gathering and Tentative Proposal. Angewandte Chemie International Edition 43 (33):4312-4318. doi:10.1002/anie.200460695

5. Brombacher S, Edmonds S, Volmer DA (2002) Studies on azaspiracid biotoxins. II. Mass spectral behavior and structural elucidation of azaspiracid analogs. Rapid Commun Mass Spectrom 16 (24):2306-2316. doi:10.1002/rcm.863

6. James KJ, Sierra MD, Lehane M, Magdalena AB, Furey A (2003) Detection of five new hydroxyl analogues of azaspiracids in shellfish using multiple tandem mass spectrometry. Toxicon 41 (3):277-283. doi:Pii S0041-0101(02)00288-X

7. Rehmann N, Hess P, Quilliam MA (2008) Discovery of new analogs of the marine biotoxin azaspiracid in blue mussels (Mytilus edulis) by ultra-performance liquid chromatography/tandem mass spectrometry. Rapid Commun Mass Sp 22 (4):549-558. doi:10.1002/rcm.3385

8. Ofuji K, Satake M, McMahon T, Silke J, James KJ, Naoki H, Oshima Y, Yasumoto T (1999)

Two analogs of azaspiracids isolated from mussels, Mytilus edulis, involved in human intoxication in Ireland. Natural Toxins 7:99-102

9. Ofuji K, Satake M, McMahon T, James KJ, Naoki H, Oshima Y, Yasumoto T (2001)

Structures of azaspiracid analogs, azaspiracid-4 and azaspiracid-5, causative toxins of azaspiracid poisoning in Europe. Biosci Biotechnol Biochem 65 (3):740-742

10. Furey A, Moroney C, Magdalena AB, Saez MJF, Lehane M, James KJ (2003) Geographical, temporal, and species variation of the polyether toxins, azaspiracids, in shellfish. Environmental Science \& Technology 37 (14):3078-3084. doi:Doi 10.1021/Es020246z

11. James KJ, Furey A, Lehane M, Ramstad H, Aune T, Hovgaard P, Morris S, Higman W, Satake M, Yasumoto T (2002) First evidence of an extensive northern European distribution of azaspiracid poisoning (AZP) toxins in shellfish. Toxicon 40 (7):909-915. doi:S004101010200082X [pii]

12. Magdalena A, Lehane M, Krys S, Fernandez M, Furey A, James K (2003) The first identification of azaspiracids in shellfish from France and Spain. Toxicon 42 (1):105-108. doi:10.1016/s0041-0101(03)00105-3

13. Torgersen T, Bremnes NB, Rundberget T, Aune T (2008) Structural confirmation and

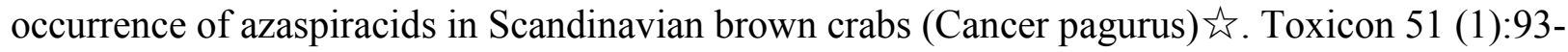
101. doi:10.1016/j.toxicon.2007.08.008

14. Taleb H, Vale P, Amanhir R, Benhadouch A, Sagou R, Chafik A (2006) First detection of azaspiracids in mussels in north west Africa. J Shellfish Res 25 (3):1067-1070 
15. Trainer V, Moore L, Bill B, Adams N, Harrington N, Borchert J, da Silva D, Eberhart B-T (2013) Diarrhetic Shellfish Toxins and Other Lipophilic Toxins of Human Health Concern in Washington State. Marine Drugs 11 (6):1815-1835. doi:10.3390/md11061815

16. Ueoka R, Ito A, Izumikawa M, Maeda S, Takagi M, Shin-ya K, Yoshida M, van Soest RWM, Matsunaga S (2009) Isolation of azaspiracid-2 from a marine sponge Echinoclathria sp. as a potent cytotoxin. Toxicon 53 (6):680-684. doi:10.1016/j.toxicon.2009.02.008

17. Krock B, Tillmann U, John U, Cembella A (2008) LC-MS-MS aboard ship: tandem mass spectrometry in the search for phycotoxins and novel toxigenic plankton from the North Sea. Analytical and Bioanalytical Chemistry 392 (5):797-803. doi:10.1007/s00216-008-2221-7 18. Tillmann U, Elbrachter M, Krock B, John U, Cembella A (2009) Azadinium spinosum gen. et sp. nov. (Dinophyceae) identified as a primary producer of azaspiracid toxins. Eur J Phycol 44 (1):63-79. doi:10.1080/09670260802578534

19. Salas R, Tillmann U, John U, Kilcoyne J, Burson A, Cantwell C, Hess P, Jauffrais T, Silke J (2011) The role of Azadinium spinosum (Dinophyceae) in the production of azaspiracid shellfish poisoning in mussels. Harmful Algae 10 (6):774-783. doi:10.1016/j.hal.2011.06.010 20. McCarron P, Kilcoyne J, Miles CO, Hess P (2009) Formation of Azaspiracids-3, -4, -6, and 9 via Decarboxylation of Carboxyazaspiracid Metabolites from Shellfish. J Agr Food Chem 57 (1):160-169. doi:10.1021/jf8025138

21. Jauffrais T, Marcaillou C, Herrenknecht C, Truquet P, Sechet V, Nicolau E, Tillmann U, Hess P (2012) Azaspiracid accumulation, detoxification and biotransformation in blue mussels (Mytilus edulis) experimentally fed Azadinium spinosum. Toxicon : official journal of the International Society on Toxinology 60:582-595. doi:10.1016/j.toxicon.2012.04.351 22. Hess P, Nguyen L, Aasen J, Keogh M, Kilcoyne J, McCarron P, Aune T (2005) Tissue distribution, effects of cooking and parameters affecting the extraction of azaspiracids from mussels, , prior to analysis by liquid chromatography coupled to mass spectrometry. Toxicon 46 (1):62-71. doi:10.1016/j.toxicon.2005.03.010 23. Anonymous (2004) Regulation (EC) No 853/2004 of the European parliament and of the council of 29 April 2004 laying down specific hygiene rules for food of animal origin. Official Journal of the European Union L 139 of 30 April 2004

24. Authority EFS (2008) Marine biotoxins in shellfish - Azaspiracid group. Scientific Opinion of the Panel on Contaminants in the Food Chain. vol 723.

25. Hess P, Butter T, Petersen A, Silke J, McMahon T (2009) Performance of the EUharmonised mouse bioassay for lipophilic toxins for the detection of azaspiracids in naturally contaminated mussel (Mytilus edulis) hepatopancreas tissue homogenates characterised by liquid chromatography coupled to tandem mass spectrometry. Toxicon 53 (7-8):713-722.

doi:10.1016/j.toxicon.2009.02.015

26. Anonymous (2011) Commission Regulation (EU) No 15/2011 of 10 January 2011 amending Regulation (EC) No 2074/2005 as regards recognised testing methods for detecting marine biotoxins in live bivalve molluscs. Official Journal of the European Union L 006 of 11 January 2011: 3-6

27. Forsyth CJ, Xu JY, Nguyen ST, Samdal IA, Briggs LR, Rundberget T, Sandvik M, Miles CO (2006) Antibodies with broad specificity to azaspiracids by use of synthetic haptens. Journal of the American Chemical Society 128 (47):15114-15116. doi:Doi 10.1021/Ja066971h 28. McCarron P, Giddings SD, Miles CO, Quilliam MA (2011) Derivatization of azaspiracid biotoxins for analysis by liquid chromatography with fluorescence detection. Journal of Chromatography A 1218:8089-8096. doi:10.1016/j.chroma.2011.09.017 
29. Perez RA, Rehmann N, Crain S, LeBlanc P, Craft C, MacKinnon S, Reeves K, Burton IW, Walter JA, Hess P, Quilliam MA, Melanson JE (2010) The preparation of certified calibration solutions for azaspiracid-1, -2 , and -3 , potent marine biotoxins found in shellfish. Anal Bioanal Chem 398 (Copyright (C) 2011 American Chemical Society (ACS). All Rights Reserved.):22432252. doi: $10.1007 / \mathrm{s} 00216-010-4161-2$

30. Quilliam MA, Reeves K, MacKinnon S, Craft C, Whyte H, Walter J, Stobo L, Gallacher S Preparation of reference materials for azaspiracids. In: 5th International Conference of Molluscan Shellfish Safety, 14-18 June 2004, Galway, Ireland, Molluscan Shellfish Safety, 2006. vol ISBN: 1 902895-33-9. pp 111-115

31. Turner AD, Lewis AM, Hatfield RG, Higman WA, Burrell S (2013) A feasibility study into the production of a freeze-dried oyster reference material for paralytic shellfish poisoning toxins. Anal Bioanal Chem 405 (26):8621-8632. doi:10.1007/s00216-013-7273-7

32. McCarron P, Kotterman M, de Boer J, Rehmann N, Hess P (2007) Feasibility of gamma irradiation as a stabilisation technique in the preparation of tissue reference materials for a range of shellfish toxins. Analytical and Bioanalytical Chemistry 387 (7):2487-2493.

doi:10.1007/s00216-006-0935-y

33. Bogialli S, Dicorcia A (2007) Matrix solid-phase dispersion as a valuable tool for extracting contaminants from foodstuffs. Journal of Biochemical and Biophysical Methods 70 (2):163-179. doi:10.1016/j.jbbm.2006.07.007

34. Mountfort DO, Suzuki T, Truman P (2001) Protein phosphatase inhibition adapted for determination of total DSP in contaminated mussel. Toxicon 39:383-390

35. McCarron P, Giddings SD, Quilliam MA (2011) A mussel tissue certified reference material for multiple phycotoxins. Part 2: liquid chromatography-mass spectrometry, sample extraction and quantitation procedures. Analytical and Bioanalytical Chemistry 400 (3):835-846.

doi:10.1007/s00216-011-4803-z

36. Hardstaff WR, Jamieson WD, Milley JE, Quilliam MA, Sim PG (1990) Reference materials for domoic acid, a marine neurotoxin. Fresenius J Anal Chem 338:520-525

37. Hess P, McCarron P, Quilliam MA (2007) Fit-for-purpose shellfish reference materials for internal and external quality control in the analysis of phycotoxins. Analytical and Bioanalytical Chemistry 387 (7):2463-2474. doi:10.1007/s00216-006-0792-8

38. McCarron P, Burrell S, Hess P (2007) Effect of addition of antibiotics and an antioxidant on the stability of tissue reference materials for domoic acid, the amnesic shellfish poison.

Analytical and Bioanalytical Chemistry 387 (7):2495-2502. doi:10.1007/s00216-006-0833-3

39. McCarron P, Emteborg H, Hess P (2007) Freeze-drying for the stabilisation of shellfish toxins in mussel tissue (Mytilus edulis) reference materials. Analytical and Bioanalytical Chemistry 387 (7):2475-2486. doi:10.1007/s00216-006-1104-z

40. McCarron P, Emteborg H, Giddings SD, Wright E, Quilliam MA (2011) A mussel tissue certified reference material for multiple phycotoxins. Part 3: homogeneity and stability. Analytical and Bioanalytical Chemistry 400 (3):847-858. doi:10.1007/s00216-011-4787-8 41. van der Veen AMH, Linsinger T, Pauwels J (2001) Uncertainty calculations in the certification of reference materials. 2. Homogeneity study. Accred Qual Assur 6:26-30 42. Nzoughet K, Hamilton J, Floyd S, Douglas A, Nelson J, Devine L, Elliott C (2008) Azaspiracid: First evidence of protein binding in shellfish. Toxicon 51 (7):1255-1263. doi:10.1016/j.toxicon.2008.02.016

43. Alfonso C, Rehmann N, Hess P, Alfonso A, Wandscheer CB, Abuin M, Vale C, Otero P, Vieytes MR, Botana LM (2008) Evaluation of various $\mathrm{pH}$ and temperature conditions on the 
stability of azaspiracids and their importance in preparative isolation and toxicological studies. Anal Chem 80 (24):9672-9680. doi:10.1021/ac801506d

$10.1021 / \mathrm{ac} 801506 \mathrm{~d}$ [pii]

44. Barker S (2007) Matrix solid phase dispersion (MSPD) 弥. Journal of Biochemical and Biophysical Methods 70 (2):151-162. doi:10.1016/j.jbbm.2006.06.005

45. Kilcoyne J, Fux E (2010) Strategies for the elimination of matrix effects in the liquid chromatography tandem mass spectrometry analysis of the lipophilic toxins okadaic acid and azaspiracid-1 in molluscan shellfish. Journal of Chromatography A 1217 (45):7123-7130. doi:DOI: 10.1016/j.chroma.2010.09.020

46. Fux E, Rode D, Bire R, Hess P (2008) Approaches to the evaluation of matrix effects in the liquid chromatography-mass spectrometry (LC-MS) analysis of three regulated lipophilic toxin groups in mussel matrix (Mytilus edulis). Food Additives \& Contaminants: Part A 25 (8):10241032. doi:10.1080/02652030802008601

47. Ito S, Tsukada K (2002) Matrix effect and correction by standard addition in quantitative liquid chromatographic-mass spectrometric analysis of diarrhetic shellfish poisoning toxins. $\mathrm{J}$ Chromatogr A 943 (1):39-46

48. Gerssen A, Olst EHW, Mulder PPJ, Boer J (2010) In-house validation of a liquid chromatography tandem mass spectrometry method for the analysis of lipophilic marine toxins in shellfish using matrix-matched calibration. Analytical and Bioanalytical Chemistry 397 (7):3079-3088. doi:10.1007/s00216-010-3886-2

49. Kilcoyne J, McCarron P, Twiner MJ, Nulty C, Crain S, Quilliam MA, Rise F, Wilkins AL, Miles CO (2014) Epimers of azaspiracids: Isolation, structural elucidation, relative LC-MS response, and in vitro toxicity of 37-epi-azaspiracid-1. Chem Res Toxicol 27 (4):587-600. doi: $10.1021 / \mathrm{tx} 400434 \mathrm{~b}$

50. Ihnat M (1998) A synopsis of different approaches to the certification of reference materials. Fresenius J Anal Chem 360:308-311

51. Burton IW, Quilliam MA, Walter JA (2005) Quantitative 1H NMR with External Standards: Use in Preparation of Calibration Solutions for Algal Toxins and Other Natural Products. Analytical Chemistry 77 (10):3123-3131. doi:10.1021/ac048385h

52. ISO-guide-35 (2006) Reference materials - general statistics and principles for certification. REMCO.

53. BIPM, IEC, IFCC, ISO, IUPAC, IUPAP, OIML (1995) Guide to the expression of uncertainty in measurement, 1st edition. International Organisation for Standardisation (ISO). Geneva 


\section{Tables}

Table 1. Relative concentrations of AZA1-3 monitored in the stability study on CRM-AZAMus. Values are expressed relative to day 0 samples that had been stored at the reference condition $\left(-80^{\circ} \mathrm{C}\right)$

\begin{tabular}{|c|c|c|c|c|c|}
\hline & $\begin{array}{c}\text { Time point } \\
\text { (days) }\end{array}$ & $-12^{\circ} \mathrm{C}$ & $+4^{\circ} \mathrm{C}$ & $+20^{\circ} \mathrm{C}$ & $+37^{\circ} \mathrm{C}$ \\
\hline \multirow{4}{*}{$\underset{\mathbb{Z}}{Z}$} & 14 & $1.03(0.05)$ & $1.05(0.03)$ & $1.01(0.02)$ & $0.98(0.07)$ \\
\hline & 67 & $0.98(0.09)$ & $1.06(0.07)$ & $0.97(0.09)$ & $0.92(0.13)$ \\
\hline & 144 & $1.02(0.05)$ & $0.97(0.10)$ & $1.02(0.01)$ & $0.86(0.01)$ \\
\hline & 267 & $1.00(0.02)$ & $1.01(0.02)$ & $1.00(0.07)$ & $0.87(0.09)$ \\
\hline \multirow{4}{*}{$\frac{2}{3}$} & 14 & $1.03(0.05)$ & $1.05(0.07)$ & $1.03(0.01)$ & $0.99(0.08)$ \\
\hline & 67 & $0.98(0.11)$ & $1.06(0.04)$ & $0.98(0.10)$ & $0.92(0.08)$ \\
\hline & 144 & $1.05(0.06)$ & $1.00(0.13)$ & $1.03(0.03)$ & $0.87(0.06)$ \\
\hline & 267 & $0.97(0.08)$ & $1.01(0.01)$ & $1.04(0.09)$ & $0.93(0.11)$ \\
\hline \multirow{4}{*}{$\frac{3}{3}$} & 14 & $1.01(0.05)$ & $1.04(0.03)$ & $1.00(0.01)$ & $0.78(0.09)$ \\
\hline & 67 & $0.99(0.04)$ & $1.03(0.03)$ & $0.96(0.03)$ & $0.26(0.01)$ \\
\hline & 144 & $0.99(0.03)$ & $1.03(0.01)$ & $0.90(0.01)$ & $0.09(0.01)$ \\
\hline & 267 & $1.01(0.02)$ & $1.05(0.08)$ & $0.71(0.04)$ & $0.07(0.03)$ \\
\hline
\end{tabular}

Numbers in parentheses are standard deviations (SD, $n=3)$ 
Table 2. Concentrations $(\mathrm{mg} / \mathrm{kg})$ of AZAs in CRM-AZA-Mus determined in certification exercises. Concentrations are a sum of the main AZA compound and its C37 epimer.

\begin{tabular}{|c|c|c|c|c|}
\hline Method & Calibration & AZA1 & AZA2 & AZA3 \\
\hline \multirow{3}{*}{ 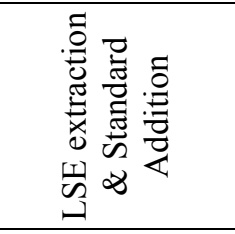 } & Standard addition & 1.184 & 0.284 & 0.225 \\
\hline & External calibration & 0.895 & 0.233 & 0.188 \\
\hline & $\%$ difference & 24.4 & 18.1 & 16.3 \\
\hline \multirow{3}{*}{ 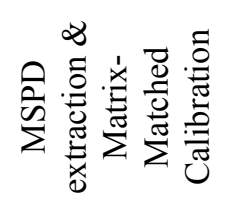 } & Matrix calibrants & 1.132 & 0.261 & 0.197 \\
\hline & $\mathrm{MeOH}$ calibrants & 0.92 & 0.219 & 0.181 \\
\hline & $\%$ difference & 18.7 & 16.2 & 8.1 \\
\hline \multirow{3}{*}{ 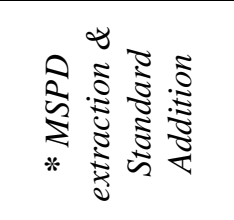 } & Standard addition & 1.101 & 0.28 & 0.202 \\
\hline & External calibration & 0.867 & 0.228 & 0.179 \\
\hline & $\%$ difference & 21.3 & 18.4 & 11.5 \\
\hline \multirow{3}{*}{ 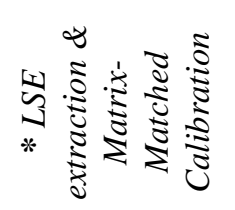 } & Matrix calibrants & 1.129 & 0.284 & 0.212 \\
\hline & MeOH calibrants & 0.878 & 0.229 & 0.195 \\
\hline & $\%$ difference & 22.3 & 19.4 & 8.08 \\
\hline
\end{tabular}

*data not used in assignment of certified values for CRM-AZA-Mus in italics 
Table 3. The certified values, estimated standard uncertainties for the individual components, and combined uncertainty estimates for AZA1, AZA2 and AZA3. Certified concentrations $(\mathrm{mg} / \mathrm{kg})$ taken from LSE standard addition data and MSPD matrix-matched calibration data are a sum of the main AZA compound and its C37 epimer.

\begin{tabular}{cccc}
\hline & AZA1 & AZA2 & AZA3 \\
\hline Certified values $(\mathrm{mg} / \mathrm{kg})$ & 1.16 & 0.27 & 0.21 \\
Combined uncertainty $(\mathrm{k}=2)$ & 0.09 & 0.02 & 0.02 \\
\hline$\mu_{\text {char }}$ & 0.029 & 0.008 & 0.009 \\
$\mu_{\text {homo }}$ & 0.04 & 0.006 & 0.007 \\
$\mu_{\text {stab }}$ & 0.014 & 0.006 & 0.001 \\
\hline
\end{tabular}


Table 4. Information values for additional AZA analogues present in CRM-AZA-Mus and relative retention times

\begin{tabular}{cccc}
\hline Analog & {$[\mathbf{M + H}]^{+}$} & $\mathbf{R R T}^{*}$ & $\mathbf{~ m g} / \mathbf{k g} * *$ \\
\hline AZA1 & 842.5 & 1.00 & - \\
AZA2 & 856.5 & 1.04 & - \\
AZA3 & 828.5 & 0.93 & - \\
AZA4 & 844.5 & 0.77 & 0.16 \\
AZA5 & 844.5 & 0.83 & 0.04 \\
AZA6 & 842.5 & 0.97 & 0.08 \\
AZA7 & 858.5 & 0.83 & 0.02 \\
AZA8 & 858.5 & 0.86 & 0.03 \\
AZA9 & 858.5 & 0.81 & 0.04 \\
AZA10 & 858.5 & 0.87 & 0.02 \\
\hline
\end{tabular}

* RRTs relating to AZA1 using LC-MS method 3.

** Information values only: these concentrations are not certified 
Table 5. Information values for other lipophilic toxins in CRM-AZA-Mus.

\begin{tabular}{ccc}
\hline Toxin & {$[\mathbf{M + H}]^{+}$} & $\mathbf{~ m g / k g *}$ \\
\hline OA & 805.5 & $0.08(0.13)^{* *}$ \\
DTX2 & 805.5 & $0.01(0.01)^{* *}$ \\
SPX C & 706.5 & 0.01 \\
YTX & 1143.5 & 0.01 \\
13-desMe-SPX C & 692.5 & trace \\
\hline
\end{tabular}

* These concentrations are not certified

** Values in parentheses are total amounts of OA and DTX2 determined following base hydrolysis 


\section{Figure Captions}

Fig. 1. Structure and $m / z$ values for the $[\mathrm{M}+\mathrm{H}]^{+}$ions of selected AZA analogues

Fig. 2. Schematic of CRM-AZA-Mus preparation, bottling and stabilization process.

Fig. 3. Concentrations of AZA1-3 measured in aliquots $(n=3)$ of uncooked mussel tissue after heating at different temperatures. Error bars shown represent \pm 1 SD.

Fig. 4: LC-MS/MS chromatogram for AZA1-3 and AZA6 in CRM-AZA-Mus using neutral pH (A) and acidic $\mathrm{pH}(\mathrm{B})$ mobile phases, showing resolution and co-elution of 37-epi-AZAs, respectively.

Fig. 5. LC-MS/MS analysis for selected additional AZA analogs present in CRM-AZA-Mus. 


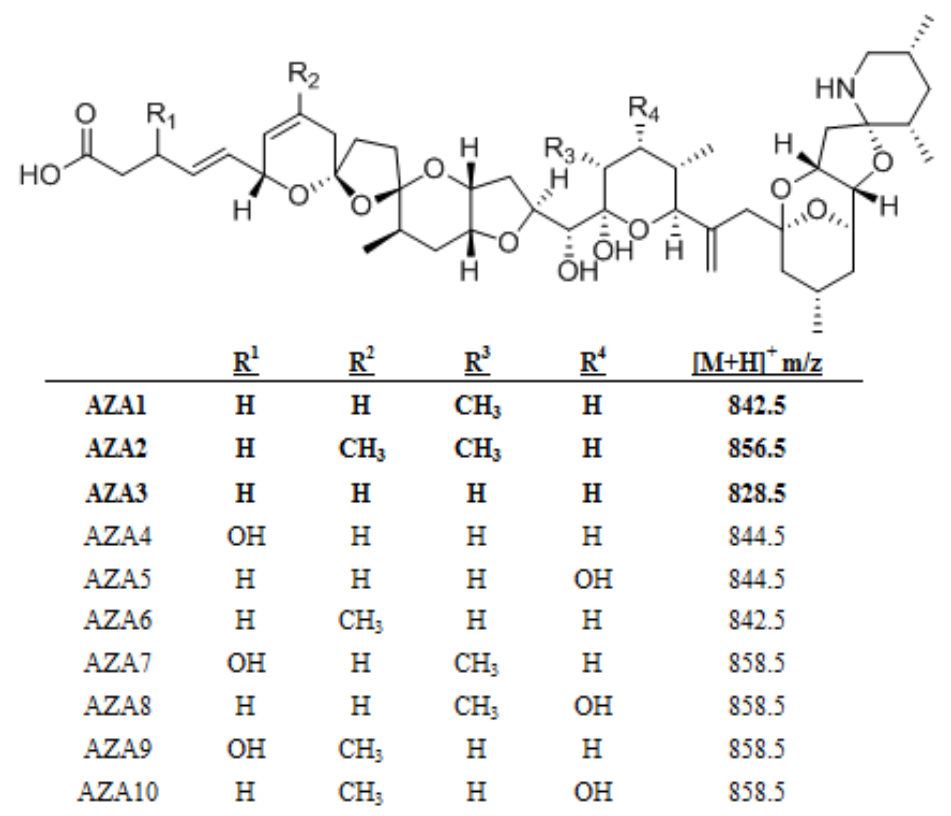

Fig. 1. 


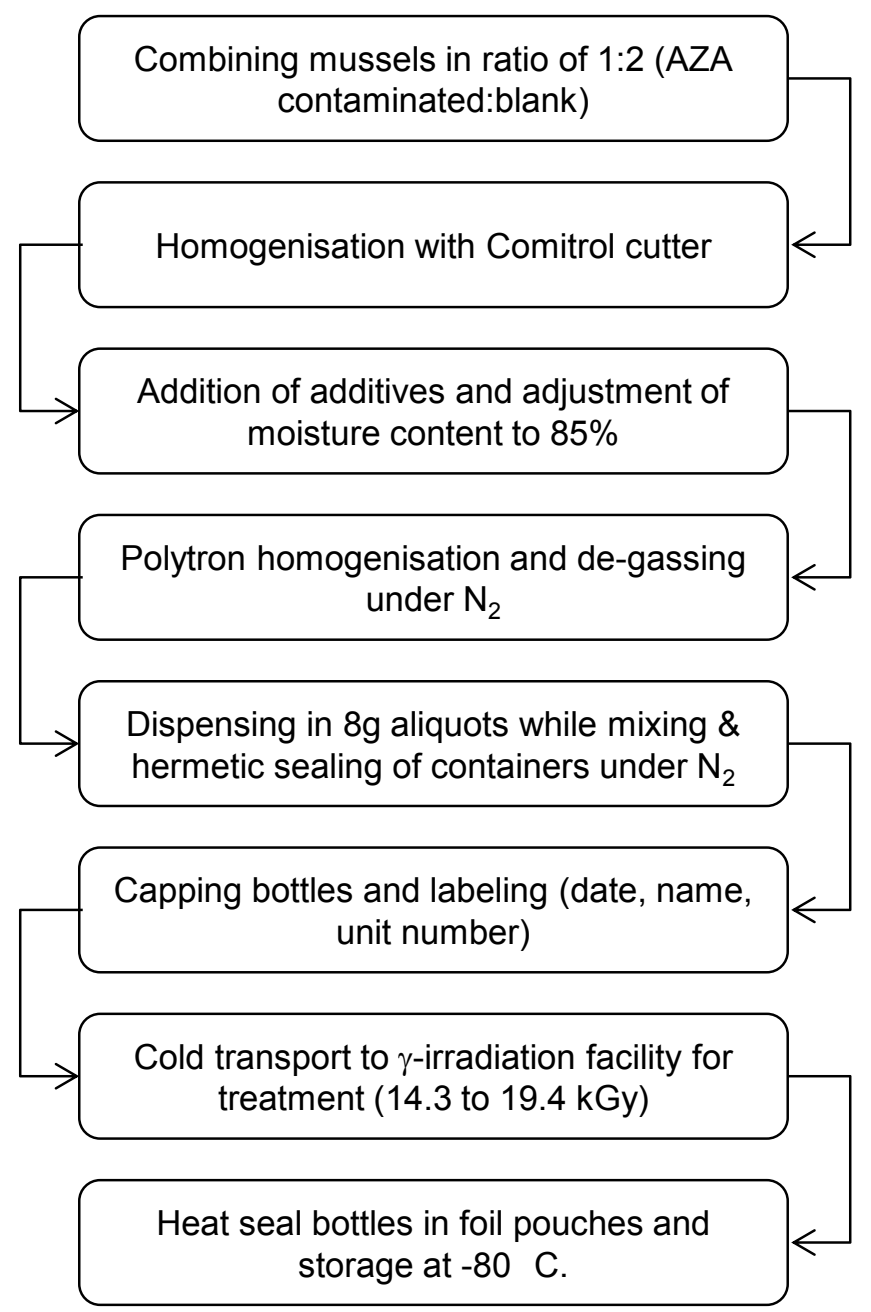

Fig. 2. 


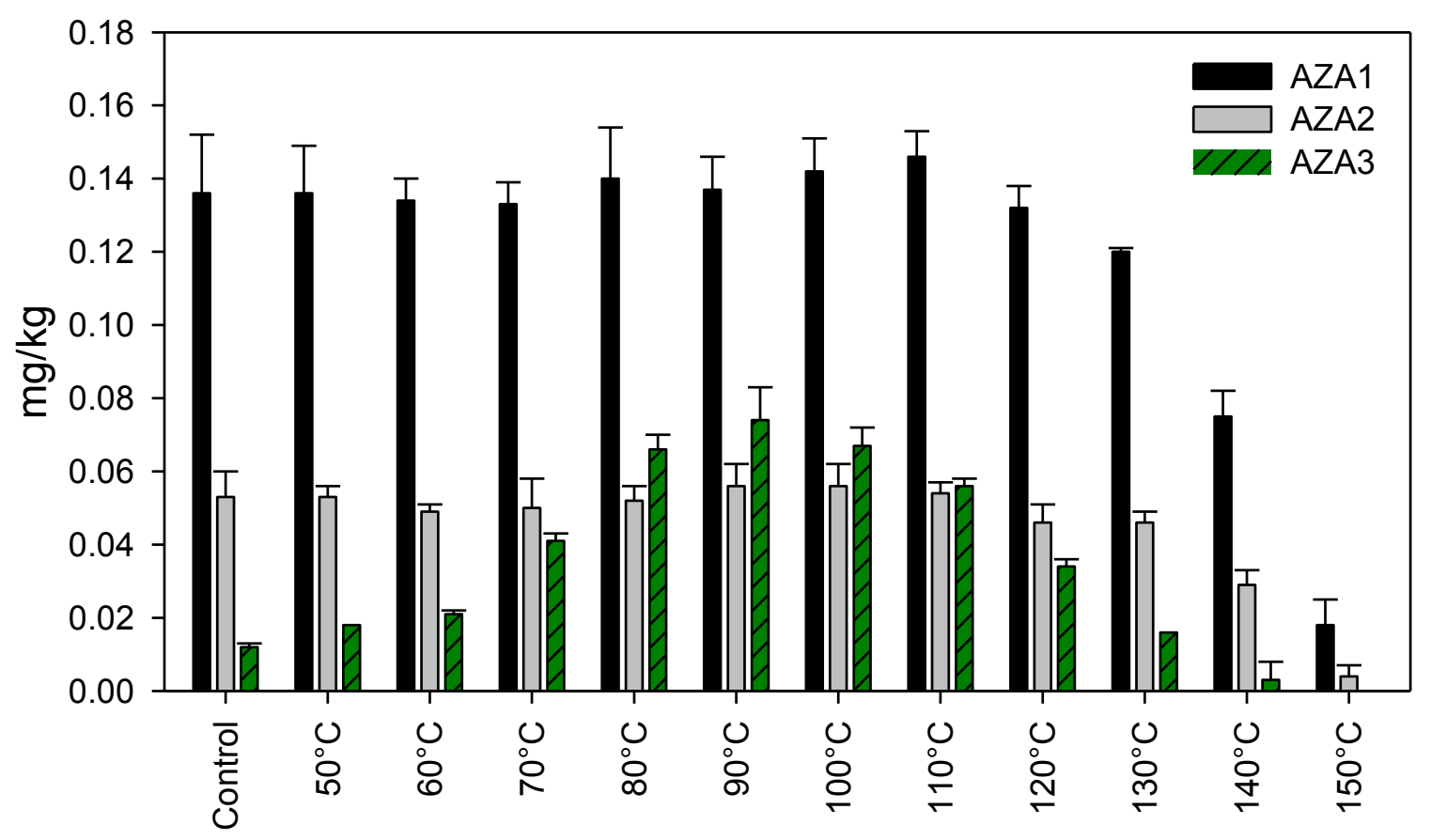

Fig. 3. 

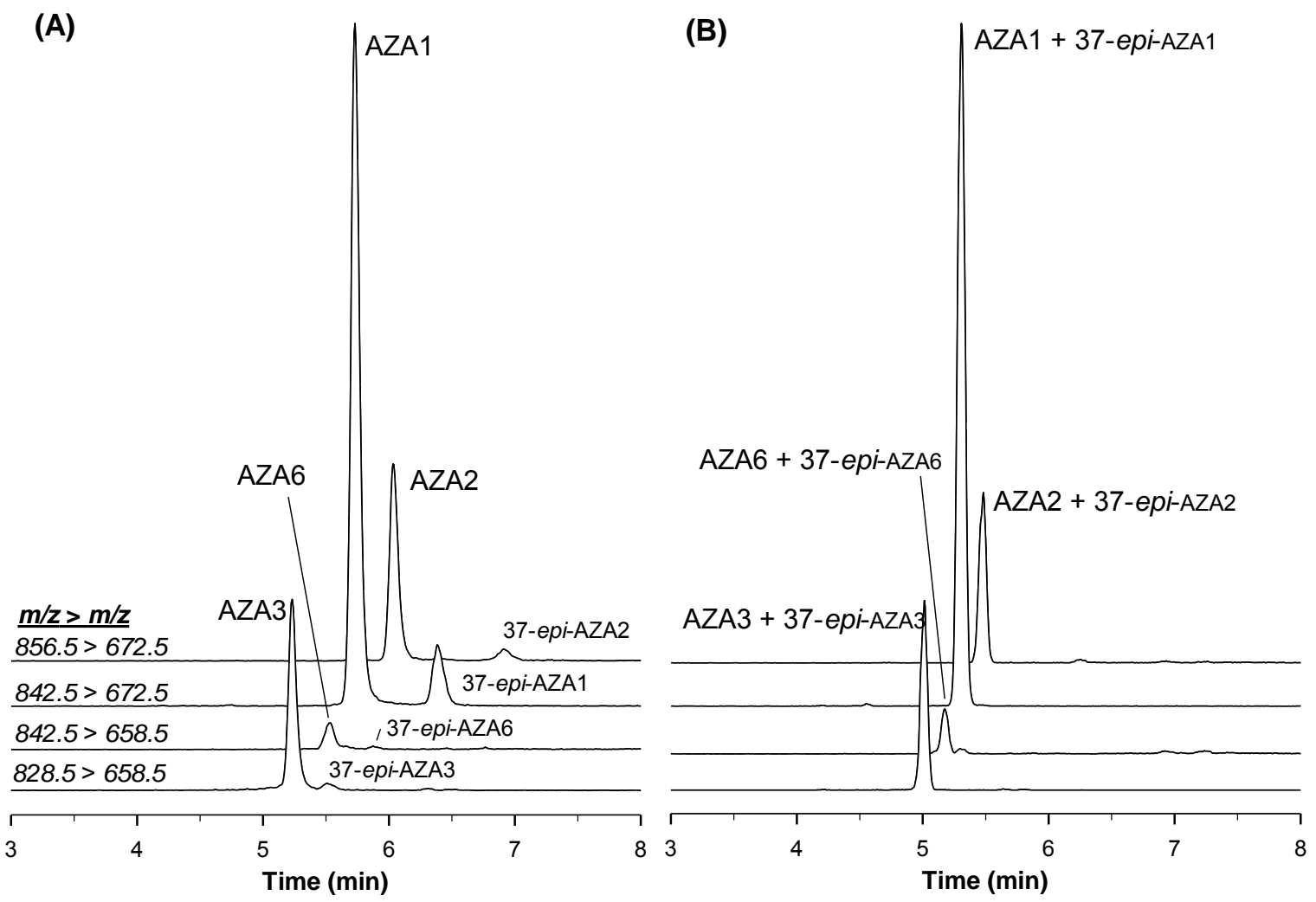

Fig. 4 


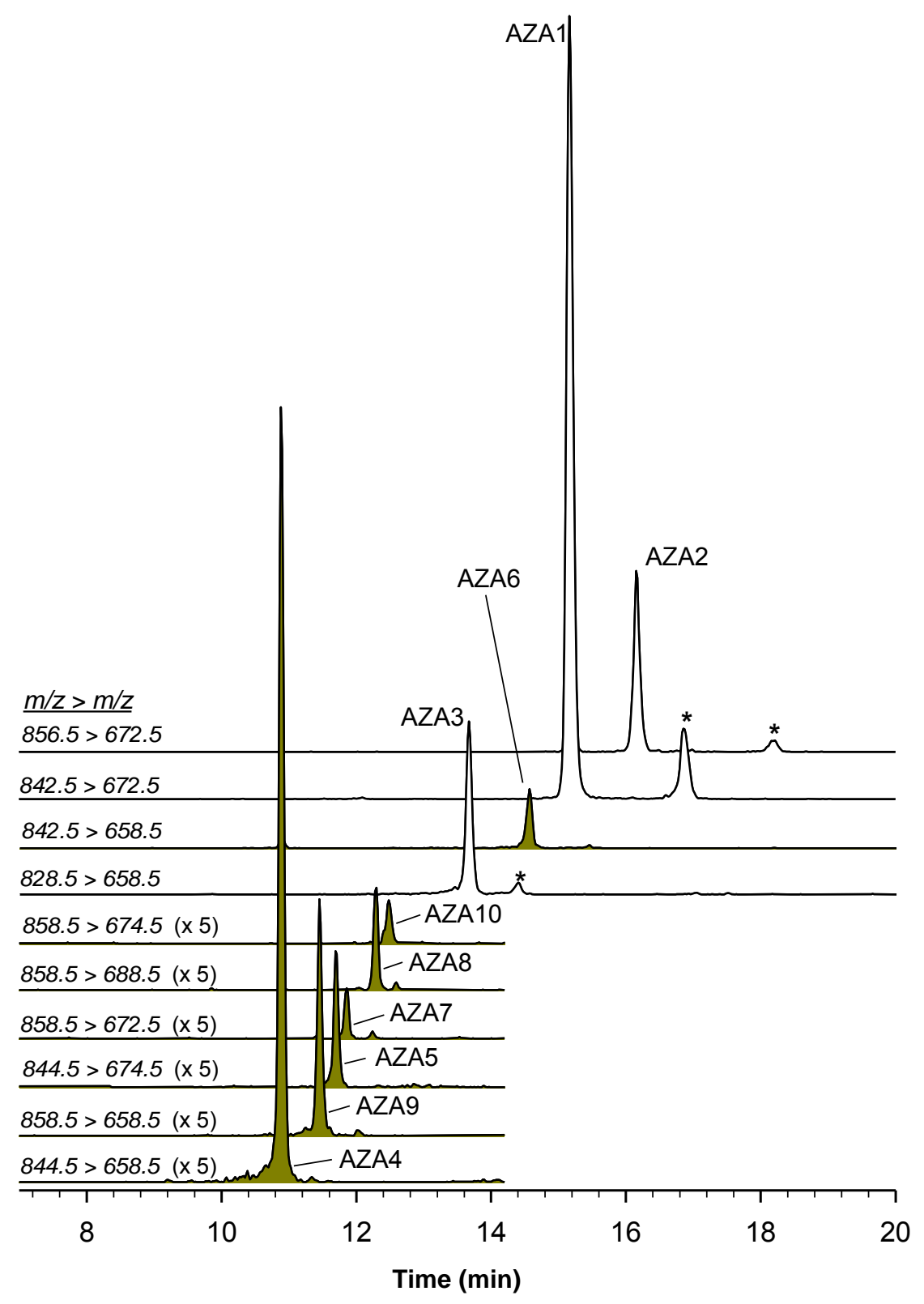

Fig. 5 